\title{
Hammerstein, Notker, Geschichte als Arsenal. Ausgewählte Aufsätze zu Reich, Hof und Universitäten der Frühen Neuzeit
}

Boris Klein

\section{OpenEdition}

Journals

Édition électronique

URL : http://journals.openedition.org/ifha/6647

DOI : 10.4000/ifha.6647

ISSN : 2198-8943

Éditeur

IFRA - Institut franco-allemand (sciences historiques et sociales)

Référence électronique

Boris Klein, «Hammerstein, Notker, Geschichte als Arsenal. Ausgewählte Aufsätze zu Reich, Hof und Universitäten der Frühen Neuzeit », Revue de l'IFHA [En ligne], Date de recension, mis en ligne le 01 janvier 2011, consulté le 22 septembre 2020. URL : http://journals.openedition.org/ifha/6647 ; DOI https://doi.org/10.4000/ifha.6647

Ce document a été généré automatiquement le 22 septembre 2020.

(CIFHA 


\title{
Hammerstein, Notker, Geschichte als Arsenal. Ausgewählte Aufsätze zu Reich, Hof und Universitäten der Frühen Neuzeit
}

\author{
Boris Klein
}

Au cours de sa longue carrière d'enseignant et de chercheur, N.H. s'est affirmé comme l'un des principaux spécialistes allemands de l'histoire de l'Empire, des universités et de l'éducation à l'époque moderne. Il y a dix ans déjà paraissait un premier volume rassemblant un grand nombre de ses articles, ce qui permettait de mieux saisir sa méthode et ses grands points de réflexion, en marge de ses ouvrages devenus des classiques, comme Jus und Historie (1972). À l'occasion de son quatre-vingtième anniversaire, c'est aujourd'hui un second recueil qui vient de paraître, présenté par M. Maaser et $\mathrm{G}$. Walther, deux de ses anciens élèves. Les dix-huit articles rassemblés couvrent l'ensemble de la période d'activité de N.H., de sa leçon inaugurale en décembre 1968 à Francfort sur la pensée politique de von Moser, à un texte récent de 2008, méditation pleine de recul et de finesse sur la liberté académique. Si l'on peut regretter que l'introduction ne soit qu'un rapide hommage n'explicitant pas clairement les choix d'articles effectués, ni la structure du recueil, le parti pris de ne pas présenter les textes dans un ordre chronologique, tout comme celui de conserver l'aspect original de certaines communications orales s'avèrent fructueux. Ces choix permettent en effet de découvrir, ou de redécouvrir facilement certains grands textes, sans être tenté par la recherche d'une évolution globale forcément réductrice. La clarté de l'expression et des problématiques, ainsi que le souci permanent d'exposer les relations entre l'État moderne en construction et la question de l'éducation, ressortent en permanence. Surtout, l'exigence d'historien de N.H. s'affirme clairement, notamment à la lecture du texte de 1983 qui donne son titre au recueil : parler de l'histoire comme d'un arsenal en regardant l'époque moderne, c'est ne pas se contenter de présenter les idées des penseurs de l'époque, mais c'est essayer de retrouver leurs motivations profondes, les buts qu'ils donnaient à leurs actions et à leurs textes. Entre l'évolution intellectuelle et 
la signification, le but politique, N.H. ne cesse de tisser des liens. Si l'on retrouve plusieurs textes portant sur ses grands thèmes de prédilection, comme les universités, les grands penseurs (Leibniz, Thomasius, Wolff, Möser...) ou les représentations modernes de l'Empire, le recueil recèle aussi quelques agréables surprises. Le goût de l'auteur pour l'Italie se dévoile dans un texte de 1984 sur les traités d'architecture de la Renaissance et la notion d'utopie urbaine, inspiré de sa collaboration avec August Buck. Enfin, le recueil se clôt sur un texte stimulant de 1986, consacré à la pratique de la musique au sein des cours princières : au-delà de son intérêt propre, cet ultime article rappelle la variété et l'originalité des travaux de N.H., autant qu'il souligne son rôle de pionnier au cœur des années 1970-1980. Au fil des jubilés, l'ampleur de l'œuvre, sa capacité à franchir tous types de frontières et son caractère étonnamment contemporain se dévoilent donc, pour le plus grand bonheur des historiens modernistes.

Boris Klein (université Lyon II) 